\title{
Spenden an das Röntgen-Geburtshaus - jetzt auch per App
}

Ab sofort können Sie Ihre Spende komfortabel per App an die Geburtshaus-WilhelmConrad-Röntgen-Stiftung senden. Möglich macht das die App „spendino“. Mit nur wenigen Klicks können Sie sich sicher sein, dass das Geld richtig ankommt.

Verfügbar ist die App für Android und iOS, jeweils im App bzw. Play Store.

Mit dem Erwerb des Geburtshauses von Wilhelm Conrad Röntgen durch die Deutsche Röntgengesellschaft und mit der Gründung einer Stiftung für die Pflege die- ses Hauses und des Andenkens von W. C. Röntgen war ein erster Schritt getan, diesen historischen Ort zu erhalten und mit neuen Ideen zu füllen. Nach der umfassenden Sanierung fungiert das Haus nun als lebendiges Denkmal und inspirierender Ort, der von Besucherinnen und Besuchern aus aller Welt erlebt werden kann.

Mehr zum Hintergrund und der aktuellen Nutzung erfahren Sie auf www.roentgen-geburtshaus.de.

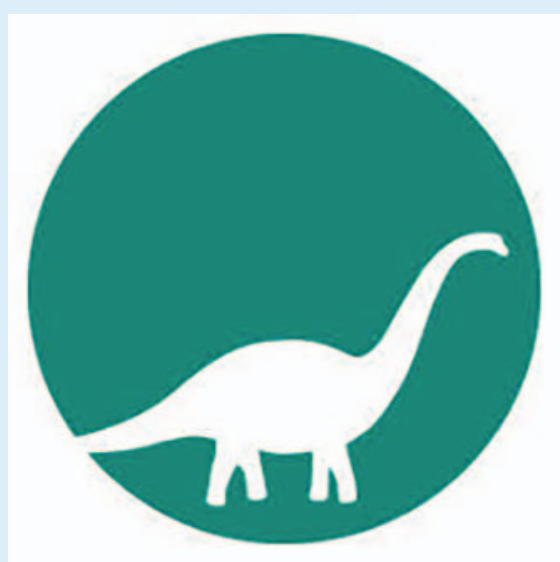

